\title{
HUBUNGAN ANTARA PENGETAHUAN TENTANG ANEMIA PADA IBU HAMIL TRIMESTER II DAN III DENGAN RESIKO TERJADINYA ANEMIA DALAM KEHAMILAN DI PUSKESMAS SUKORAME KEDIRI
}

\author{
Rabitha Rachmaniar ${ }^{1}$, Halida Nelasari ${ }^{2}$, Bambang Widiwanto ${ }^{3}$
}

Fakultas Kedokteran Universitas Muhammadiyah Malang, Jl. Bendungan Sutami No. 188A, Malang, 65145, Indonesia, 0341-551149

\begin{abstract}
ABSTRAK
Hubungan Antara Pengetahuan Tentang Anemia Pada Ibu Hamil Trimester II dan III dengan Resiko Terjadinya Anemia dalam Kehamilan di Puskesmas Sukorame Kediri. Latar Belakang: Tingkat pengetahuan ibu hamil yang rendah menimbulkan resiko anemia dalam kehamilan. Tujuan: Mengetahui hubungan pengetahuan tentang anemia pada ibu hamil dengan resiko terjadinya anemia dalam Metode: Observasional analitik dengan pendekatan Cross Sectional. Hasil dan Diskusi: Hasil uji Chi - Square yang menunjukkan nilai X2 = 7,108 dengan nilai signifikansi $(p=0,029)$ $<0,05$. Kesimpulan: Terdapat hubungan antara pengetahuan ibu hamil tentang anemia pada ibu hamil trimester II dan III dengan resiko terjadinya anemia dalam kehamilan di Puskesmas Sukorame Kediri.
\end{abstract}

\section{ABSTRACT}

The Relationship between The Knowledge of Anemia in Pregnant Trimester II and III with the Risk of Anemia in Pregnancy in Puskesmas Sukorame Kediri. Introduction: Pregnant women with low level of knowledge greatly affect how they keep their pregnancy. One of the risk is anemia in pregnancy. Objective: to prove the relationship between the knowledge of anemia in with the risk of anemia in pregnancy. Method: use observational analytical research with cross sectional approach. Result: The result from Chi - Square statistical test showed the value of $X 2=7.108$ with a significance value $(p=0.029)<0.05$. Conclusion: There was a relationship between the knowledge of pregnant women about anemia in pregnant trimester II and III with the risk of anemia in pregnancy in Puskesmas Sukorame Kediri.

Key word : knowledge, anemia, pregnant trimester II and III

\section{PENDAHULUAN}

Tingkat pengetahuan ibu hamil yang rendah sangat mempengaruhi bagaimana ia menjaga kehamilannya. Adanya mitos bahwa ibu hamil pantang mengonsumsi makanan tertentu menyebabkan sebagian besar ibu hamil tidak mengonsumsi makanan yang merupakan sumber gizi baginya. Perilaku seseorang atau masyarakat tentang kesehatan ditentukan oleh pengetahuan, sikap, kepercayaan, dan tradisi dari orang yang bersangkutan. Pengetahuan yang dimiliki ibu hamil tentang anemia dan kehamilan dapat membantu dalam merawat dirinya dan kandungannya secara baik dan sesuai (Mulyati., et al, 2007).

Anemia sering terjadi akibat defisiensi zat besi karena pada ibu hamil terjadi peningkatan kebutuhan zat besi dua kali lipat akibat peningkatan volume darah tanpa ekspansi volume plasma, untuk memenuhi kebutuhan ibu dan pertumbuhan janin (Fatimah, St., et al, 2011). Dampak anemia pada janin antara lain abortus, terjadi kematian intauterin, prematuritas, berat badan lahir rendah, cacat bawaan dan mudah infeksi. Pada ibu, saat kehamilan dapat mengakibatkan abortus, persalinan prematuritas, ancaman dekompensasi kordis dan ketuban pecah dini. Pada saat persalinan dapat mengakibatkan gangguan his, retensio plasenta dan perdarahan post partum karena atonia uteri (Manuaba, 2007).
Sebagian besar wanita mengalami anemia selama kehamilan, baik di negara berkembang maupun negara maju. WHO melaporkan bahwa sekitar 35\% sampai 75\% (rata-rata 65\%) dari wanita hamil di negara berkembang mengalami anemia selama kehamialan, sedangkan di negara maju hanya 18\% (Allen, 2000). Wanita hamil merupakan salah satu kelompok yang rentan masalah gizi terutama masalah anemia gizi besi. Berdasarkan Survei Kesehatan Rumah Tangga (SKRT) pada tahun 2001 menunjukkan $40,1 \%$ ibu hamil menderita anemia dan pada tahun 2007 turun menjadi 24,5\% (Rikerdas, 2007). Namun demikian, keadaan ini mengindikasiakan bahwa anemia gizi besi masih menjadi masalah kesehatan masyarakat (Kemenkes RI, 2010). Mengacu pada uraian di atas maka penulis merasa terdorong untuk melakukan penelitian di Puskesmas Sukorame Kediri, Kediri merupakan salah satu kota yang menjalin kerja sama dengan Fakultas Kedokteran Universitas Muhammadiyah Malang melalui rumah sakit pendidikan.

Penelitian ini bertujuan untuk mengetahui hubungan antara pengetahuan tentang anemia pada ibu hamil trimester II dan III dengan resiko terjadinya anemia dalam kehamilan di Puskesmas Sukorame Kediri. 


\section{METODE}

Penelitian ini merupakan penelitian analitik observasional menggunakan studi kasus cross sectional untuk menilai hubungan antara pengetahuan tentang anemia pada ibu hamil dengan resiko terjadinya anemia dalam kehamilan di Puskesmas Sukorame Kediri. Penelitian akan dilaksanakan di Puskesmas Sukorame Kediri pada bulan Februari 2012 Populasi dalam penelitian ini adalah seluruh ibu hamil yang memeriksakan kehamilannya di Puskesmas Sukorame Kediri. Sampel yang dipilih untuk penelitian ini adalah ibu hamil trimester II dan III yang memeriksakan kehamilannya di Puskesmas Sukorame Kediri. Teknik pengambilan sampel dalam penelitian ini menggunakan metode Non-Probability Sampling dengan teknik Consecutive Sampling. Consecutive Sampling yaitu pemilihan sample dengan menetapkan subjek yang memenuhi kriteria penelitian dimasukkan dalam penelitian sampai kurun waktu tertentu, sehingga jumlah responden dapat terpenuhi (Sastroasmoro, 2010).

Kriteria inklusi pada penelitian ini adalah ibu hamil trimester II dan III yang memeriksakan kehamilannya di Puskesmas Sukorame Kota Kediri. Sedangkan untuk kriteria eksklusi pada penelitian ini ibu hamil trimester II dan III yang memeriksakan kehamilannya di Puskesmas Sukorame Kota Kediri.

Instrumen yang digunakan dalam penelitian ini adalah dengan menggunakan kuesioner dan pemerikssaan hemoglobin dengan menggunakan $\mathrm{Hb}$ Mindray BC-2600 Auto Hematology Analyzer.

Data penelitian diperoleh adalah data primer meliputi pengetahuan anemia yang diperoleh dengan kuesioner serta hasil pemeriksaan kadar hemoglobin yang diperoleh melalui pemeriksaan hemoglobin dengan menggunakan $\mathrm{Hb}$ Mindray BC-2600 Auto Hematolgy Analyzer dan darah diambil dari darah kapiler ujung jari pada yang menjadi responden. Dalam pemeriksaan dan pembacan kadar hemoglobin ini bekerja sama dengan petugas laboratorium di Puskesmas Sukorame Kediri.

Data dikelompokkan menjadi 2 kelompok yaitu ibu hamil trimester II dan III dengan pengetahuan tentang anemia yang cukup dan ibu hamil trimester II dan III dengan pengetahuan tentang anemia yang kurang, kemudian dikelompokkan lagi menjadi 2 kelompok yaitu ibu hamil trimester II dan III yang anemia dan ibu hamil trimester II dan III yang normal. Untuk mengetahui adanya hubungan antara pengetahuan tentang anemia pada ibu hamil dengan resiko terjadinya anemia dalam kehamilan analisa data dilakukan secara bivariat dengan mengunakan uji Chi - square SPSS.

\section{HASIL DAN PEMBAHASAN}

Penelitian dilakukan terhadap 97 ibu hamil trimester II dan III yang memeriksakan kehamilannya di Puskesmas Sukorame Kediri. Data diperoleh berdasarkan hasil jawaban kuesioner untuk mengetahui tingkat pengetahuan ibu hamil tentang anemia, dan untuk mengetahui resiko terjadinya anemia dalam kehamilan diperoleh dari hasil pemeriksaan kadar hemoglobin. Data diolah sesuai dengan tujuan penelitian untuk mengetahui adanya hubungan antara pengetahuan tentang anemia pada ibu hamil trimester II dan III dengan resiko terjadinya anemia dalam kehamilan di Puskesmas Sukorame Kediri. Peneliti menyadari masih adanya keterbatasan dalam penelitian ini yaitu tidak disertai dengan meneliti faktor-faktor lain yang mempengaruhi anemia dalam kehamilan, yaitu umur ibu, tingkat pendidikan, pekerjaan, ekonomi, paritas, jarak kehamilan, status gizi, kepatuhan konsumsi tablet $\mathrm{Fe}$, dan infeksi parasit.

Dalam penelitian ini pengetahuan responden dibagi menjadi tiga, yaitu pengetahuan baik, pengetahuan cukup dan pengetahuan kurang. Dalam penelitian ini didapatkan hasil yaitu sebanyak 20 responden $(20,6 \%)$ berpengetahuan baik, sebanyak 37 responden $(38,1 \%)$ berpengetahuan cukup sedangkan sebanyak 40 responden $(41,2 \%)$ berpengengetahuan kurang.

Kadar hemoglobin dikategorikan menjadi anemia $(<10$ $\mathrm{g} / \mathrm{dl})$ dan tidak anemia $(>10 \mathrm{~g} / \mathrm{dl})$. Berdasarkan penelitian ini didapatkan bahwa responden yang anemia sebanyak 48 responden $(49,5 \%)$ dan responden yang tidak anemia sebanyak 49 responden (50,5\%). Tabel 5.2 menyajikan distribusi responden berdasarkan status anemia ibu hamil di Puskesmas Sukorame Kediri.

Hasil penelitian menunjukkan bahwa ibu hamil yang memiliki pengetahuan tentang anemia baik sebanyak 20 orang $(20,6 \%)$, dimana 7 orang $(7,2 \%)$ mengalami anemia dan 13 orang $(13,4 \%)$ tidak mengalami anemia, ibu hamil yang memiliki pengetahuan anemia cukup sebanyak 37 orang $(38,1 \%)$, dimana 14 orang $(14,4 \%)$ mengalami anemia dan 23 orang $(23,7 \%)$ tidak mengalami anemia sedangkan ibu hamil yang memiliki pengetahuan anemia kurang sebanyak 40 orang $(41,2 \%)$, dimana 27 orang $(27,8 \%)$ mengalami anemia dan 13 orang $(13,4 \%)$ tidak mengalami anemia. Sehingga dapat dikatakan bahwa ibu hamil yang memiliki pengetahuan tentang anemia kurang akan meningkatkan resiko terjadinya anemia dalam kehamilan, dibandingkan mereka yang memiliki pengetahuan tentang anemia baik dan cukup.

Pengujian hipotesis dengan menggunakan uji Chi - Square (tabulasi silang) memberikan hasil X2 $=8,880$, nilai signifikansi $(p)=0,012(p<0,05)$, artinya terdapat hubungan antara pengetahuan tentang anemia pada ibu hamil trimester II dan III dengan resiko terjadinya anemia dalam kehamilan di Puskesmas Sukorame Kediri.

Pada penelitian Herdiani (2010), untuk mengukur pengetahuan ibu hamil tentang anemia dengan menggunakan pertanyaan tentang anemia sejumlah 6 pertanyaan. Teknik yang digunakan dalam memperoleh data primer adalah teknik angket langsung yaitu disampaikan langsung kepada orang yang dimitai informasi dan yang mengisi adalah responden langsung. Sedangkan pada penelitian ini peneliti mengukur pengetahuan ibu hamil tentang anemia menggunakan 30 pertanyaan tentang anemia. Hal ini diharapkan bisa menggali lebih dalam sejauh mana pengetahuan ibu hamil tentang anemia. Teknik dalam memperoleh data primer yang digunakan oleh peneliti dalam penelitian ini yaitu teknik angket langsung dengan didampingi oleh peniliti dengan tujuan jika ada responden yang kesulitan dalam memahami pertanyaan bisa menanyakannya. 
Penelitian Herdiani (2010), pengetahuan responden dikategorikan menjadi dua, yaitu rendah dan tinggi. Dikatakan pengetahuan rendah jika nilai responden < median sedangakan pengetahuan tinggi jika nilai responden $<$ median. Nilai median 10,0. Berbeda dari penelitian Herdiani (2010), pada penelitian ini pengetahuan responden dikategorikan menjadi tiga, yaitu baik, cukup, dan kurang.

Hal ini didasarkan pada hasil akhir suatu pengetahuan menurut (Nursalam, 2008) dikategorikan dengan tingkatan pengetahuan baik jika jawaban benar 76-100\%, pengetahuan cukup jika jawaban benar 56-76\% dan berpengetahuan kurang jika jawaban benar kurang dari 56\%.

Dalam penelitiannya, Herdiani (2010) menggunakan kriteria diagnosa anemia dalam kehamilan adalah apabila kadar hemoglobin ibu hamil <11 gr/dl, sedangkan pada penelitian penulis menggunakan kriteria diagnosa anemia dalam kehamilan apabila kadar hemoglobin ibu hamil $<10$ gr/dl. Hal ini didasarkan pada anemia pada wanita tidak hamil didefinisikan sebagai konsentrasi hemoglobin yang kurang dari $12 \mathrm{~g} / \mathrm{dl}$ dan kurang dari $10 \mathrm{~g} / \mathrm{dl}$ selama kehamilan atau masa nifas (Cunningham., et al, 2006). Alasan praktis kriteria anemia di klinik untuk Indonesia pada umumnya adalah (Bakta, 2007) hemoglobin $<10 \mathrm{~g} /$ $\mathrm{dl}$, hal ini dipertimbangkan untuk mengurangi beban klinisi melakukan work up anemia jika kita memakai kriteria WHO.

Dalam penelitian ini, sampel yang diambil adalah ibu hamil trimester II dan III hal ini didasarkan pada, perbedaan kadar $\mathrm{Hb}$ yang sesuai dengan bertambahnya usia kehamilan ini dapat terjadi karena perubahan hematologi sehubungan dengan kehamilan, antara lain adalah peningkatan kebutuhan oksigen karena pertumbuhan janin, perubahan sirkulasi yang makin meningkat terhadap plasenta dan janin, serta kebutuhan suplai darah untuk pembesaran uterus, sehingga terjadi peningkatan volume darah yaitu peningkatan volume plasma dan sel darah merah. Namun, peningkatan volume plasma terjadi dalam proporsi yang lebih besar jika dibandingkan dengan peningkatan volume sel darah merah sehingga terjadi penurunan konsentrasi hemoglobin akibat hemodilusi. Bila hal ini terjadi terusmenerus, terjadi ketidakseimbangan yaitu timbullah anemia pada kehamilan (Abdulmuthalib, 2008).

Dalam penelitiannya, Riswan (2003) yang melaporkan bahwa dari 60 wanita hamil, didapatkan 32 orang (53,3\%) mengalami anemia dengan distribusi 4 orang $(20 \%)$ pada trimester I, 14 orang $(70 \%)$ pada trimester II, dan 14 orang $(70 \%)$ pada trimester III dengan kriteria anemia $<11$ gr. Pengetahuan yang dimiliki ibu hamil tentang kehamilan dapat membantu dalam merawat dirinya dan kandungannya secara baik dan sesuai termasuk dalam hal pemilihan jenis makanan yang dikonsumsi setiap harinya sehingga resiko yang dapat mengakibatkan dampak buruk bagi ibu dan bayi dapat dihindarkan (Mulyati, 2007).

Menurut teori Lawrence Green dalam (Notoatmodjo, 2007), pengetahuan seseorang tentang kesehatan merupakan salah satu faktor presdidposisi yang mempengaruhi perilaku seseorang, jadi jika ibu hamil tidak mendapatkan informasi atau penyuluhan tentang anemia maka dapat berpengaruh dalam bagaimana ibu hamil tersebut menghindarkan dirinya dari anemia. Pengetahuan merupakan faktor yang penting untuk terbentuknya perilaku seseorang, karena dari pengalaman dan penelitian terbukti bahwa perilaku yang didasari pengetahuan akan lebih langgeng dari perilaku yang tidak didasari oleh pengetahuan. Dengan meningkatnya pengetahuan ibu hamil tentang anemia diharapkan akan terjadi perubahan perilaku ke arah yang mendukung kesehatan (Notoatmodjo, 2007).

Menurut Notoatmodjo (2007) faktor-faktor yang dapat mempengaruhi kurangnya pengetahuan ibu hamil tentang anemia dalam kehamilan antara lain kurangnya informasi dari tenaga kesehatan kepada ibu hamil, kurang jelasnya informasi yang disampaikan oleh tenaga kesehatan kepada ibu hamil, kurangnya kemampuan ibu hamil untuk memahami informasi yang diberikan. Peningkatan pengetahuan tentang anemia dapat diperoleh melalui saran informasi baik elektronik (televisi, radio) maupun media cetak (koran, majalah) dan juga dapat diperoleh melalui penyuluhan-penyuluhan tentang kesehatan untuk ibu-ibu agar terhindar dari suatu penyakit terutama anemia pada ibu hamil yang dilakukan oleh petugas kesehatan maupun kader kesehatan. Dalam hal ini sesuai dengan pernyataan Notoatmodjo (2007), bahwa pengetahuan tidak hanya diperoleh dari pendidikan formal tetapi juga dari pendidikan informal.

\section{SIMPULAN}

Berdasarkan hasil penelitian yang telah dilakukan, maka dapat ditarik kesimpulan sebagai berikut yaitu terdapat hubungan antara pengetahuan tentang anemia pada ibu hamil trimester II dan III dengan resiko terjadinya anemia dalam kehamilan di Puskesmas Sukorame Kediri, jumlah ibu hamil trimester II dan III yang memiliki pengetahuan yang baik tentang anemia di Puskesmas Sukorame Kediri sebesar 20 orang (20,6\%), jumlah ibu hamil trimester II dan III yang memiliki pengetahuan yang cukup tentang anemia di Puskesmas Sukorame Kediri sebesar 37 orang (38,1\%), jumlah ibu hamil trimester II dan III yang memiliki pengetahuan yang kurang tentang anemia di Puskesmas Sukorame Kediri sebesar 40 orang (41,2\%), jumlah ibu hamil trimester II dan III yang menderita anemia di Puskesmas Sukorame Kediri sebesar 49,5\%.

Berdasarkan hasil pengujian yang telah dilakukan dari penelitian ini dapat diketahui bahwa ada hubungan yang signifikan antara pengetahuan ibu hamil tentang anemia pada ibu hamil trimester II dan III dengan resiko terjadinya anemia dalam kehamilan. Sehingga diberikan beberapa saran yang dapat menjadi bahan pertimbangan dan masukan sebagai berikut yaitu perlu diadakan penyuluhan tentang anemia dalam kehamilan sehingga diharapkan dengan meningkatnya pengetahuan tentang anemia ibu hamil akan memperhatikan kesehatannya dan prevalensi anemia dalam kehamilan dapat berkurang.

\section{DAFTAR PUSTAKA}

Abdulmuthalib, 2008, Kelainan Hematologik, Dalam: Saifuddin AB, Rachimhadhi T, Wiknjosastro GH (editor), 2008, Ilmu Kebidanan Sarwono Prawirohardjo, PT Bina Pustaka Sarwono Prawirohardjo, Jakarta, hal. 775-778. 
Ahmed F, Mahmuda I, Sattar A, et al, 2003, Anemia and Vitamin A Deficiency in Poor Urban Pregnant Women of Bangladesh, Asia-Pac J Clin Nutr, Vol 12, No.4, hal. 460-466, diakses tanggal 31 Januari 2012, <http:// www.ncbi.nlm.nih.gov/pubmed/14672871>.

Aikawa R, Ngyen C Khan, Satoshi Sasaki, et al, 2006, Risk Factors for Irondeficiency Anaemia among Pregnant Women Living in Rural Vietnam, Public Health Nutrition, Vol. 9, No. 4, hal. 443-448, diakses tanggal 31 Januari 2012, <http://journals. cambridge. org/ download. php? file=\%2 FPHN\%2FPHN9_0 4\%2FS1368980006000772a.pdf\& code $=$ a1e4a3c 52c488252533e 435a6523 a1b7 >

Allen, Lindsay H, 2000, Anemia and Iron Deficiency: Effects On Pregnancy Outcome, The American Jurnal of Clinical Nutrition, Vol. 71, diakses 31 Januari 2012, <http://www.ajcn.org/content/71/5/1280S.full.pdf>.

Almatsier S, 2009, Prinsip Dasar Ilmu Gizi, Geramedia Pustaka Utama, Jakarta, hal. 20.

Amiruddin R, Wahyuddin, 2004. Studi Kasus Kontrol Faktor Biomedis Terhadap Kejadian Anemia Ibu Hamil di Puskesmas Bantimurung, Jurnal Medika Nusantara, Vol. 25, No. 2, diakses tanggal 14 september 2011, $<$ http:// med.unhas.ac.id/index.php? option=com_content\&view=article\&id $=160$ :studikasus-kontrol-faktor-biomedis-terhadap-kejadian-anemia-ibuhamil-di-puskesmas-bantimurung\&catid $=101 \&$ Itemid $=48>$.

Arikunto S, 2010, Prosedur Penelitian Suatu Pendekatan Praktek, Rineka Cipta, Jakarta, hal. 211.

Bakta, I Made, 2006, Hematologi Klinik Ringkas, EGC, Jakarta, hal. 11-13, 1517, 26, 30.

Choi JW, Pai SH, 2001, Changes in Erythropoesis with Gestasional Age During Normal Pregnancy, Ann Hematol, Vol. 80, hal. 26.

Christensen R.D, Ohls R.K, 2004, Anemias Unique to Pregnancy and The Perinatal Period, Dalam: Greer J.P, Rodgers G.M, Foerster J, et al (editor), 2004, Wintrobe's Clinical Hematology, Eleventh Edition, Volume 1, Lippincott Williams \& Wilkins, Philadelphia, hal. 14671468.

Cunningham FG, Gant NF, Leveno KJ, et al, 2010, Obstetri Williams Volume 2, edisi 21, EGC, Jakarta, hal. 14631465.

Cunningham FG, Gant NF, Leveno KJ, et al, 2010, Obstetri Williams Volume 1, edisi 21, EGC, Jakarta, hal. 193.

Dan A Petrovici, Christopher Ritson, 2006, Factors Influencing Consumer Dietary Health Preventative Behaviours, BMC Public Health, Vol. 6, No. 222, diakses 9 Februari 2012, <http://www. biomedcentral. com/14712458/6/222>.

DeMaeyer, E.M, 1994, Preventing and Controlling Iron Deficiency Anemia through Primary Health Care, WHO, Geneva.

Departemen Kesehatan RI, 1999, Pedoman Pemberian Besi bagi Petugas, Ditjen Bina Kesehatan Masyarakat, Jakarta.

Departemen Kesehatan RI, 2003, Program Penanggulangan Anemia Gizi Pada WUS (Wanita Usia Subur), Departemen Kesehatan RI, Jakarta.
Dinkes Propinsi Jawa Timur dan IAKMI Pusat, 2002, Survei Data Dasar Pengetahuan, sikap dan perilaku WUS tentang Anemia dan TTD Di 10 Lokasi SMPFA di Propinsi Jawa Timur dan Jawa Tengah, Dinkes Propinsi Jawa Timur dan IAKMI, Surabaya.

Djaja S, 2003, Penyebab Kematian Bayi Baru Lahir dan Sistem Pelayanan Kesehatan yang Berkaitan di Indonesia, Badan Litbang Kesehatan, Departemen Keshatan RI, diakses 19 September 2011, <http:// digilib.litbang.depkes.go.id/go.php?id=jkpkbppk-gdlres-2003 sarimawar-881-neonatal>.

Erna Francin Paath, Rumdasih, Heryati, 2005, Gizi Dalam Kesehatan Reproduksi, EGC, Jakarta, hal. 30.

Fairbanks, Virgil F, Beutler E, 2005, Iron Deficiency, Dalam: Beutler E, Litchma Marshal A, Barry S, et al, 2005, Williams Hematology, 7th edition, McGraw-Hill, USA, hal. 449.

Fatimah, St., Hadju V, Bahar B, et al, 2011, Pola Konsumsi dan Kadar Hemoglobin Pada Ibu Hamil di Kabupaten Maros, Sulawesi Selatan, Makara, Kesehatan, Vol. 15, No. 1, hal. 31-36.

Gandahusada, dkk, 2007, Parasitologi Kedokteran, Edisi Ketiga, Fakultas Kedokteran Universitas Indonesia, Jakarta. Greer JP, Foerster J, Lukens JN, et al (editor), 2004, Wintrobe's Clinical Hematology, 11th edition, Lippincott Williams \& Wilkins, Philadelphia, hal. 449.

Guyton AC, Hall JE, 2007, Buku Ajar Fisiologi Kedokteran (Textbook of Medical Physiology), edisi 11, EGC, Jakarta, hal. 448. Harmening, DM., 2002, Clinical Hematology and Fundamental of Hemostasis, 4th edition, Davis Company, Philadelphia.

Hillman RS, Ault KA, 2002, Hematology in Clinical Practices. A Guide to Diagnosis and Management, 3rd edition, International Edition, McGraw Hill Inc, New York.

Hoffbrand AV, Petit JE, Moss PAH, 2001, Essential Hematology, 4th edition, Blackwell Scientific Publications, Oxford.

Husaini MA, Husaini YK, Siagian UL, Suharno D, 1989, Anemia Gizi: Suatu Studi Kompilasi Informasi dalam Menunjang Kebijaksanaan Nasional dan Pengembangan Program, Direktorat Bina Gizi Masyarakat dan Puslitbang Gizi, Jakarta.

Jallaluddin, Abdullah, 2002, Filsafat Pendidikan, Penerbit Gaya Media Pratama, Jakarta. Kementrian Kesehatan RI, 2011, Profil Kesehatan Indonesia 2010, Kementrian Kesehatan RI, Jakarta, hal. 125.

Manuaba, I.B.G., Manuaba, I.A. Chandranita., Manuaba, I.B.G. Fajar., 2007, Pengantar Kuliah Obstetri, EGC, Jakarta, hal. 38-39.

Milman N, Byg KG, Agger AO, 2000, Hemoglobin and Erythrocyte indices During Normal Pregnancy and Postpartum in 206 Women with and without Iron Supplementation, Acta Obstet Gynecol Scand, Vol. 79, hal. 89.

Mochtar, Rustam., Lutan, Delfi (editor), 1998, Sinopsis Obstetri Jilid 1, edisi 2, EGC, Jakarta, hal. 59.

Mulyati, Ginting F.R.R, Bahagiawati H, Aizahroni, 2007, Hubungan Antara Pengetahuan tentang Anemia dan Asupan Gizi Pada Ibu Hamil dengan Risiko Terjadinya Anemia dalam Kehamilan di Puskesmas Kecamatan 
Kembangan Jakarta Barat Periode 10-18 Desember 2007, Ebers Papyrus, Vol. 13, No. 4, hal. 171, 175.

Murray RK, Granner DK, Rodwell VW, 2003, Biokimia Harper, edisi 25, EGC, Jakarta.

Nabili S (author), Shiel WC Jr (editor), 2008, Anemia, diakses 1 Februari 20011, <http://www. medicine net.com/anemia/page8.htm\#9whatis>.

Naibaho, Sri Agnes, 2011, Faktor-Faktor Yang Berhubungan Dengan Kejadian Anemia Gizi Besi Pada Ibu Hamil Di Wilayah Kerja Puskesmas Parsoburan Kec. Habinsaran Kabupaten Toba Samosir, diakses 7 Desember 2011, <http://repository.usu.ac.id/bitstream/123456789/ 30073/7/Cover.pdf $>$.

National Heart Lung and Blood Institute, 2010, Anemia, diakses 1 Februari 2011, <http://www.nhlbi.nih.gov/ health/health-topics/topics/anemia/signs.html>.

Notoatmodjo, Soekidjo, 2005, Metodologi Penelitian Kesehatan, Rineka Cipta, Jakarta, hal.10-14, 18, 120133.

Notoatmodjo, Soekidjo, 2007, Promosi Kesehatan dan Ilmu Perilaku, Rineka Cipta, Jakarta, hal. 133, 139, 140-143.

Nursalam, 2008, Konsep dan Penerapan Metodologi Penelitian Ilmu Keperawatan, Salemba Medika, jakarta, hal. 108.

Paidas M.J, Ku De-Hui W, Arkel Y.S, 2008, Hematologic Disorder In Pregnancy, Dalam: Funai E.F, Evans M.I, Lockwood C.J, 2008, High Risk Obstetrics The Requisites in Obstetrics and Gynecology, Elsevier, Philadelphia, hal. 411.

Rasmaliah, 2004, Anemia Kurang Besi Dalam Hubungan dengan Infeksi Cacing Pada Ibu Hamil, Skripsi Strata Satu Kesehatan Masyarakat, Universitas Sumatera Utara, Medan, diakses 25 Mei 2011, <http:// repository.usu.ac.id/bitstream/123456789/3676/1/ fkmrasmaliah8.pdf $>$.

Riswan, M., 2003. Anemia Defisiensi Besi Pada Wanita Hamil Di Beberapa Praktek Bidan Swasta Dalam Kota Madya Medan, Bagian Ilmu Penyakit Dalam, Universitas Sumatera Utara, Medan, diakses diakses 8 Maret 2012, <http://library.usu.ac.id/download/fk/ penydalammuhammad $\% 20$ riswan.pdf $>$

Saifuddin AB, Adriaansz G, Wiknjosastro GH, Waspodo J (editor), 2008, Buku Acuan Nasional Pelayanan Kesehatan Maternal dan Neonatal, Yayasan Bina Pustaka Sarwono Prawirohardjo, Jakarta.

Saifuddin AB, Rachimhadhi T, Wiknjosastro GH (editor), 2008, Ilmu Kebidanan Sarwono Prawirohardjo, PT Bina Pustaka Sarwono Prawirohardjo, Jakarta.

Sastroasmoro S, Madiyono B, Moeslichan S, et al, 2010, Perkiraan Besar Sampel, Dalam: Sastroasmoro, S. \& Ismael, Sofyan, 2010, Dasar-dasar Metodologi Penelitian Klinis Ed.3 Cet.2, SagungSeto, Jakarta, hal. 197-198.

Sastroasmoro S, 2010, Pemilihan Subyek Penelitian, Dalam: Sastroasmoro S, Ismael, Sofyan, 2010, Dasar-dasar Metodologi Penelitian Klinis Ed.3 Cet.2, SagungSeto, Jakarta, hal. 78-90. Silbernagl S, Lang F, 2007, Teks \& Atlas Berwarna Patofisiologi (Color Atlas of Pathophysiology), EGC, Jakarta, hal. 30.

Soekirman, 2000, Ilmu Gizi dan Aplikasinya Untuk Masyarakat, Direktorat Jenderal Pendidikan Tinggi Departemen Pendidikan Nasional, Jakarta.
Suriady, 1997, Indikasi Kehamilan Risiko Tinggi dan Upaya Menurunkan Kematian Ibu dan Perinatal, PT. Gramedia, Jakarta.

Wasnidar, 2007, Buku Saku Anemia Pada Ibu Hamil, Trans Info Media, Jakarta.

Walsh, L.V, 2008, Buku Ajar Kebidanan Komunitas (Midwifery: CommunityBased Care During the Childbearing Year), EGC, Jakarta, hal.411-412.

Wiknjosastro, G. H., 2008. Fisiologi Janin. Dalam: Saifuddin, A. B., Rachimhadhi, T., Wiknjosastro, G. H. (editor), Ilmu Kebidanan Sarwono Prawirohardjo, PT Bina Pustaka Sarwono Prawirohardjo, Jakarta. 